\title{
Matrix of sustainability of the person
}

\author{
Vyacheslav Kazankov ${ }^{1, *}$ \\ ${ }^{1}$ St. Petersburg University of the State Fire Service EMERCOM of Russia, Ceo General of First \\ Legion LLC, 198206, St. Petersburg, St. Pionerstroya, 15/2, of.85, Russia
}

\begin{abstract}
In article the matrix of an algorithm of a research of sustainability of the person is provided. 125 terms characterizing sustainability of the person are taken as a basis. Two hypotheses are for this purpose formulated. The first hypothesis tells about lack of a uniform paradigm of studying a phenomenon sustainability. The second hypothesis approves a possible general way of a research of a phenomenon of sustainability of the person in psychology. In article the factor model of sustainability of the person defining approach to formulation of a matrix is provided. Follows from a matrix that methods of the analysis and diagnostics must show numerical value of sustainability of the person. In a matrix factors of psychophysiological, psychological and psychosocial levels of living and human activity are put. Therefore, in article it is told about psychophysiological, psychological and psychosocial sustainability. They form the general sustainability of the person. In article the author suggests entering a uniform symbol of designation of sustainability of the person $-\Omega$. In the conclusion of article, the author suggests combining efforts for forming of uniform approach in a research of a phenomenon of sustainability of the person.
\end{abstract}

\section{Introduction}

In Russia tells the word "sustainability". By synonyms in the English texts is used words are: "stability", "resistance", "resilience". For understanding of material of article by different language groups, a word " sustainability"', "stability", "firmness", "resilience" is designated by a uniform symbol $-\Omega$.

The modern world contains many probabilities with various opportunities of the same event. Therefore, it is impossible to wish bigger, than to be $\Omega$ to each option of an outcome. Life often teaches us by means of stresses. Therefore, it is necessary to be able not just to remain $\Omega$, but better to become, to evolve and be positively healthy. When the person wants to achieve success and to improve personal social and living conditions on certain indicators, aiming to get under the corresponding criterion of a social niche, it is involved in the social competition to the laws and rules. Here people face different age and sex: weak and strong, with education and without it, the rich and the poor. Some aim to catch up and overtake. Others - to remain at busy heights. In this competition the long distances borrow labor and household human activity. The competition makes on us strong impact as often passes against the background of neglect to itself.

\footnotetext{
${ }^{*}$ Corresponding author: kazankov-74@,mail.ru
} 
The author of article is a practical psychologist whose activity of 20 years related to labor organization of firemen's and lifeguards' formations in the territory of the Leningrad Region of the Russian Federation. For the 20 years' experience he had to diagnose, rehabilitate, and develop any given states at firemen's and lifeguards' and victims. Personal experience of work pushed the author to analyze scientific articles in bases Scopus, Web of Science (WoS), Web of Knowledge (WoK), etc. on a perspective $\Omega$ the person.

The relevance of article is dictated by the fact that in modern psychology more often speak about $\Omega$. This statement follows from the analysis of works Lei $\mathrm{Wu}$ and Yan Tan [1], V.V. Kazankov [2], E. Barasa, R. Mbau, L. Gilson [3] on the mentioned perspective. In terms of psychology, in works V.V. Kazankov [4] and V. Kazankov, V. Gubin [5] we suggest under $\Omega$ the person to understand his ability to keep health on psychophysiological, psychological, and psychosocial levels of living under the influence of destroyers. Destroyers - all this what is directed to damage and (or) destruction of human health. Psychophysiological, psychological and psychosocial levels form the uniform physiopsychosocial system of human health.

The purpose of article is to submit for consideration of wide audience an author's matrix of an algorithm of a research $\Omega$.

In article two hypotheses are made.

Hypothesis 1. In psychology there is no general terminology and a paradigm of a research $\Omega$ the person.

Hypothesis 2. The modern psychology has enough research and practices on a phenomenon $\Omega$ the person which are possible to bringing together in a uniform matrix of an algorithm of a research, the analysis, diagnostics, development and correction $\Omega$ the person.

\section{Materials and methods}

The research was carried out in two steps.

Stage 1 . The scientific sources containing information on terminology and methods of a research $\Omega$ the person was analyzed: A. Chmitorz and M. Wenzel [6], J. Scali and C. Gandubert [7], M.A. Harris and C.E. Brett [8], S. Yasien and J.A. Nasir [9], L. CampbellSills, M.B. Stein and J. Trauma [10], Xie Y, Peng L, Zuo X and Li M [11], G.A. Bonnano and A.D. Mancini [12], M. Pęciłło [13], S. Bruce, D. Jason and C. Nasca [14], G. A. Bonanno and E.D. Diminich [15] and information in article [16] provided in bases Scopus, Web of Science (WoS), Web of Knowledge (WoK) and other analogs are taken as a basis of the analysis. Search of scientific sources was carried out on meeting in terminology and methods of a research of keywords: " sustainability", "stability", " resistance", "resilience", "psychology", "person". By results of the analysis of sources, the main directions and methods of a research, the analysis, diagnostics, development, and correction $\Omega$ the person were stated.

Stage 2. On the basis of personal experience and the analysis of scientific sources of the first stage the research algorithm matrix $\Omega$ the person was developed.

For confirmation of any given conclusions work with respondents was carried out.

The validity of scale was studied over 10 years by comparing the results of respondents in a total sample of 1200 people, where 600 people used scale (experimental sample (ES)), another 600 people did not use it (control sample (CS)). Each sample consisted of such categories of respondents as graduate students - 150 people, 75 people in each sample; firefighters - 700 people, 350 in each sample; rescuers - 200 people, 100 in each sample; police officers - 150 people, 75 in each sample. The mean age was 31 years. 


\section{Results}

Stage 1. In science any logical search begins with definition of fundamental postulates which are accepted to a starting point which validity nobody doubts. The analysis of the literature has made it possible to identify multiple definitions of psychological resilience [17]. S.M. Southwick, G.A. Bonanno, A.S. Masten, C. Panter-Brick, R. Yehuda in work [17] write that 125 definitions of different researchers are considered. All definitions do not match with each other on semantic loading. We will give several definitions from different tables of a source as an example [17].

«Resilience is the capacity to recover from extremes of trauma, deprivation, threat, or stress (Stephens); resistance referring to maintained functioning under stressful conditions and resilience describing quick or full recovery from significant decrements in functioning upon exposure to stress (Barber); resilience is the ability to recover from perceived adverse or changing situations, through a dynamic process of adaptation, influenced by personal characteristics, family, and social resources, and manifested by positive coping, control, and integration (Caldeira)» [17; table 1]. «Resilience refers to one's ability to deal with stress and adversity and is influenced by genetic, epigenetic, developmental, neurochemical, and psychosocial factors (McAllister); resilience as an ability of adults to "maintain relatively stable, healthy levels of psychological and physical functioning" (Patel); defined resilience as the ability of adults in otherwise normal circumstances, who were exposed to an isolated and potentially highly disruptive event, to maintain relatively stable and healthy levels of psychological and physical functioning and the capacity for generative experiences and positive emotions (Garcia-Dia)» [17; table 2]. «Resilience is "a process or the attainment of positive outcomes at the individual, family, and community levels despite adversity (e.g., natural disaster, terrorist attack) (Patel); resilience is a process associated with adaptive capacities and a positive history of functioning and adaptation after adversities. This dynamic process involves the interaction between biological and psychosocial factors, which makes its investigation more complex (Dias)» [17; table 4]. «Resilience is considered both as a psychological and physical aspect of coping with stress (Caldeira); resilience resources as positive psychological, behavioral, and/or social adaptation in the face of stressors and adversities that draws upon "an individual's capacity, combined with families' and communities' resources to overcome serious threats to development and health" (Dulin)» [17; table 5].

Apparently from the given selective definitions $\Omega$, each definition reveals one of the parties of characteristics of the considered phenomenon. If to take 125 offered definitions in a source [17] for $100 \%$, then the following distribution on three main levels $\Omega$ psychophysiological (58\%), psychological (29\%) and psychosocial follows (13\%). Jackson D., Firtko A. \& Edenborough M. in work [18] write that from a historical viewpoint, there are two major discourses of resilience - the physiological and psychological. S.M. Southwick, G.A. Bonanno, A.S. Masten, C. Panter-Brick, R. Yehuda in work [19] write that determinants of resilience include a host of biological, psychological, social, and cultural factors.

Psychophysiological level is the registration of the physiological reactions of an individual when $\Omega$ of a person is established by markers: cardiovascular system (blood pressure relative to normal); eye reactions and facial expressions; skin reactions (sweating), etc. Through the nervous system through feedback lines, physiological markers are interpreted by psychic markers: attention, expressed as a perception of information; thinking reflected in logic, decision-making, etc. Psychophysiological level of the person reveals the activity of: 1) body and psyche; 2) nervous system - strength, mobility, poise; 3) cognitive mental processes - sensation, perception, memory, attention. Consequently, 
psychophysiological $\Omega$ is the ability to maintain healthy performance at the psychophysiological level. $\Omega \varphi-$ is $\Omega$ at the psychophysiological level $(\varphi)$.

Psychological level is the registration of emotions and mental states of a person, when a human $\Omega$ is established by markers: valency (tone) of emotions, their intensity (strength), activity and content, which forms emotional, activation, tonic and tensile mental states with their characteristic markers. Psychological level of the person reveals the activity of: 1) mental processes - cognitive (representation, imagination, thinking, speech) and emotional (emotions, affects, feelings, mood, an emotional stress); 2) mental states - emotional, activation, tonic, tenzionny. Consequently, psychological $\Omega$ is the ability to maintain healthy performance at the psychological level. $\Omega \psi-$ is $\Omega$ at the psychological level $(\psi)$.

Psychosocial level is registration of the volitional manifestation of the orientation of the labor subject, when human $\Omega$ is registered with markers: the ability to consciously choose the actual demand, motive, with the subsequent delivery of the goal; the ability to own and control your own behavior; the presence of a worldview and beliefs, united by the concepts of «life» and «activity». Psychosocial level of the person reveals the activity of: 1) volitional mental of processes; 2) internal and external motives and feeling; 3 ) character in relation to itself, people and work. Consequently, psychosocial $\Omega$ is the ability to maintain healthy performance at the psychosocial level. $\Omega \mathrm{s}-$ is $\Omega$ at the psychosocial level (s).

Psychophysiological, psychological and psychosocial levels allow to formulate factors model of psychology of $\Omega$ (Fig. 1).

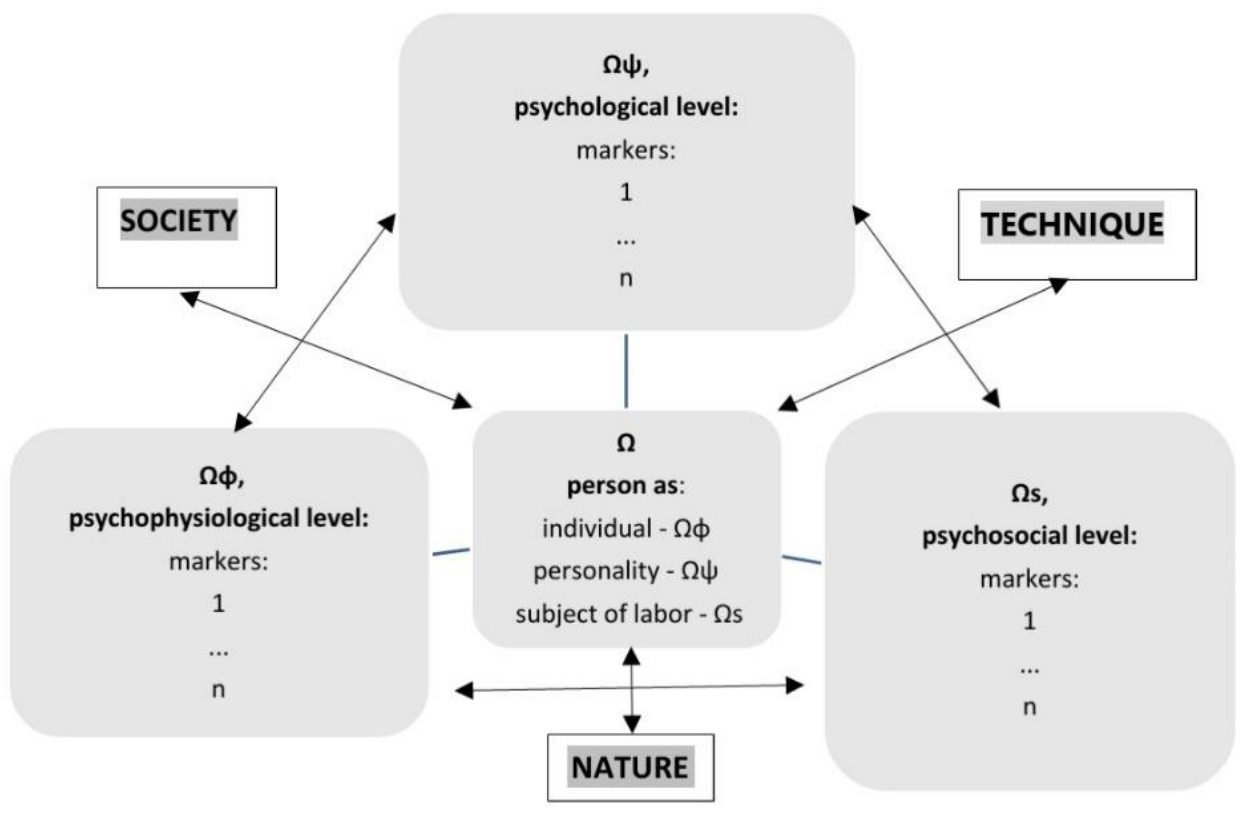

Fig. 1. Factors model of psychology of $\Omega$.

Table 1 is based on interviews with respondents. Respondents were offered to range on the importance psychophysiological, psychological and psychosocial levels concerning the life and activity. The data in table 1 (Fig. 2) indicate the possibility of an intuitive assessment and of a choice of a priority factor by respondents the psychophysiological, psychological, and psychosocial. 
Table 1. Priority factor.

\begin{tabular}{|c|c|c|c|c|c|c|c|c|c|c|c|c|c|}
\hline \multicolumn{2}{|l|}{ Middle age (years) } & \multicolumn{3}{|c|}{21} & \multicolumn{3}{|c|}{31} & \multicolumn{3}{|c|}{38} & \multicolumn{3}{|c|}{49} \\
\hline \multicolumn{2}{|l|}{ Age (years) } & \multicolumn{3}{|c|}{$18-25$} & \multicolumn{3}{|c|}{$26-35$} & \multicolumn{3}{|c|}{$36-45$} & \multicolumn{3}{|c|}{$46-55$} \\
\hline Factor & & $\varphi$ & $\psi$ & $\mathbf{S}$ & $\varphi$ & $\psi$ & $\mathbf{s}$ & $\varphi$ & $\psi$ & $\mathbf{s}$ & $\varphi$ & $\psi$ & $\mathbf{s}$ \\
\hline Students & & 11 & 45 & 44 & 35 & 51 & 14 & - & - & - & - & - & - \\
\hline Firefighters 700 & & 63 & 22 & 15 & 34 & 21 & 45 & 19 & 15 & 66 & 100 & 33 & 67 \\
\hline Rescuers & $\%$ & 55 & 22 & 23 & 37 & 24 & 39 & 19 & 23 & 58 & 100 & 39 & 61 \\
\hline $\begin{array}{ll}\begin{array}{l}\text { Police } \\
\text { officers }\end{array} & 150 \\
\end{array}$ & & 38 & 25 & 37 & 14 & 30 & 56 & 14 & 19 & 67 & 100 & 45 & 55 \\
\hline Average value (\%) & & 42 & 28.5 & 29.5 & 30 & 31.5 & 38.5 & 17.3 & 19 & 63.7 & 100 & 39 & 61 \\
\hline
\end{tabular}

The greatest $\% \quad \square$ The average $\% \quad \square$ The smallest $\%$

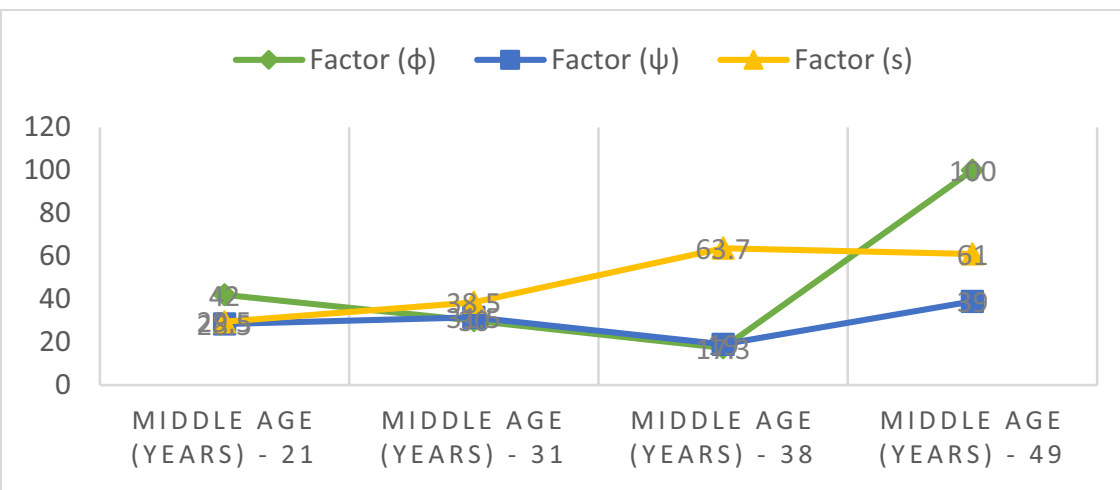

Fig. 2. Priority factors model of psychology of $\Omega$ and middle age (years) (table 1).

Stage 2. By results of stage 1 we developed a research algorithm matrix $\Omega$ the person (table 2, fig. 3). Approach of laying of an algorithm of comprehensive coverage of a research $\Omega$ the person was the main criterion of development of a matrix.

Table 2. Research algorithm matrix $\Omega$.

\begin{tabular}{|c|c|c|c|c|c|}
\hline & & 1 & 2 & 3 & \\
\hline & Factors $\Omega$ & $\Omega \varphi$ & $\mathbf{\Omega} \psi$ & $\mathbf{\Omega s}$ & Methods \\
\hline 1 & $\varphi$ & $\begin{array}{c}1-1 \\
\text { Main } \\
\text { markers }\end{array}$ & $\begin{array}{c}2-1 \\
\text { Additional } \\
\text { markers }\end{array}$ & $\begin{array}{c}3-1 \\
\text { Additional } \\
\text { markers }\end{array}$ & $\begin{array}{l}\text { Methods of the } \\
\text { analysis and } \\
\text { diagnostics }\end{array}$ \\
\hline 2 & $\psi$ & $\begin{array}{c}1-2 \\
\text { Additional } \\
\text { markers }\end{array}$ & $\begin{array}{c}2-2 \\
\text { Main } \\
\text { markers }\end{array}$ & $\begin{array}{c}3-2 \\
\text { Additional } \\
\text { markers }\end{array}$ & $\begin{array}{l}\text { Methods of the } \\
\text { analysis and } \\
\text { diagnostics }\end{array}$ \\
\hline 3 & $\mathbf{s}$ & $\begin{array}{c}1-3 \\
\text { Additional } \\
\text { markers }\end{array}$ & $\begin{array}{c}2-3 \\
\text { Additional } \\
\text { markers }\end{array}$ & $\begin{array}{c}3-3 \\
\text { Main } \\
\text { markers }\end{array}$ & $\begin{array}{l}\text { Methods of the } \\
\text { analysis and } \\
\text { diagnostics }\end{array}$ \\
\hline & Factors & $\begin{array}{l}\text { Methods of } \\
\text { development } \\
\text { and } \\
\text { correction }\end{array}$ & $\begin{array}{c}\text { Methods of } \\
\text { development } \\
\text { and } \\
\text { correction }\end{array}$ & $\begin{array}{l}\text { Methods of } \\
\text { development } \\
\text { and } \\
\text { correction }\end{array}$ & $\begin{array}{l}\text { 1. What? } \\
\text { 2. How? }\end{array}$ \\
\hline
\end{tabular}




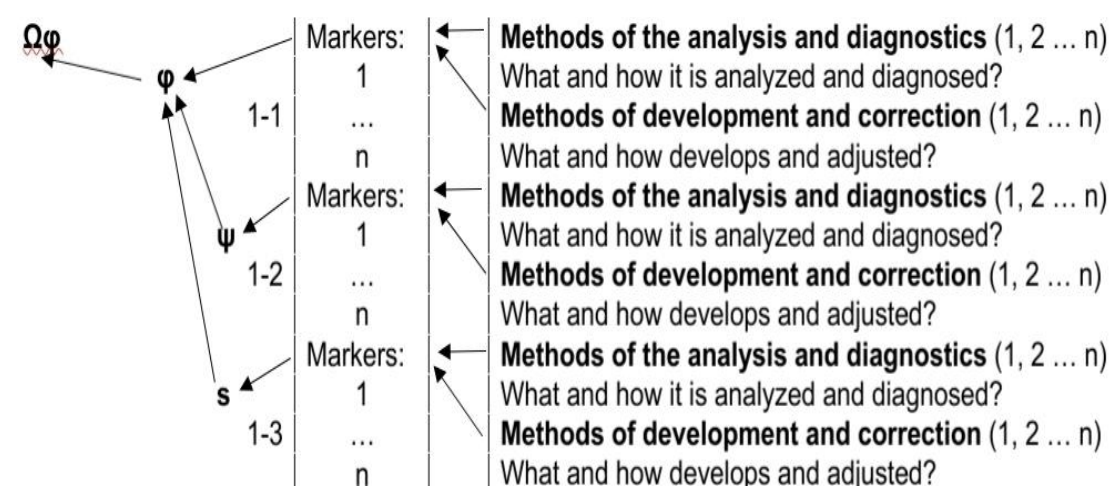

Fig. 3. The developed matrix segment on an example $\Omega \varphi$.

Methods of development and correction always follow methods of the analysis and diagnostics $\Omega$ the person.

\section{Discussion}

A number of important conclusions follows from the first stage.

The conceptual analysis of definitions $\Omega$ allows to claim the person unambiguously: the modern psychology has no uniform paradigm of a research of a phenomenon $\Omega$ the person. This statement leads to the fact that today there is no uniform terminology connected with a phenomenon $\Omega$ the person. Such situation promotes that each researcher is engaged in studying a phenomenon $\Omega$ the person at discretion without the uniform conceptual direction. This fact is not denied, for example, Fletcher D. \& Sarkar M. [20] state: «one of the main difficulties in conducting research on resilience is that wide discrepancies exist in the way that resilience is defined and conceptualized» and further «It is, therefore, important to address these definitional concerns in order to provide an understanding of why different approaches have prevailed, of the results that have emerged, and, as knowledge has accumulated, of the relative strengths and weaknesses of theoretical explanations» [20]. Not accidentally critiques on a phenomenon research $\Omega$ the person began to be published in bases Scopus, WoS, WoK, etc. collective, survey. The lack of a uniform paradigm and terminology in a research $\Omega$ leads the person to the fact that for frequent the empirical data confirming or disproving any given hypotheses and statements are not published. Undoubtedly, Peter A. D. Sherrard is right in claiming «All too often conceptual models are promoted and described in the literature with little or no empirical evidence to support the beliefs» [21].

In the scient metric reviewed bases follows from a set of the published researches that all researches concerning a phenomenon $\Omega$ the person lie in the psychophysiological, psychological and psychosocial plane of studying a phenomenon $\Omega$ the person (fig. 4). 


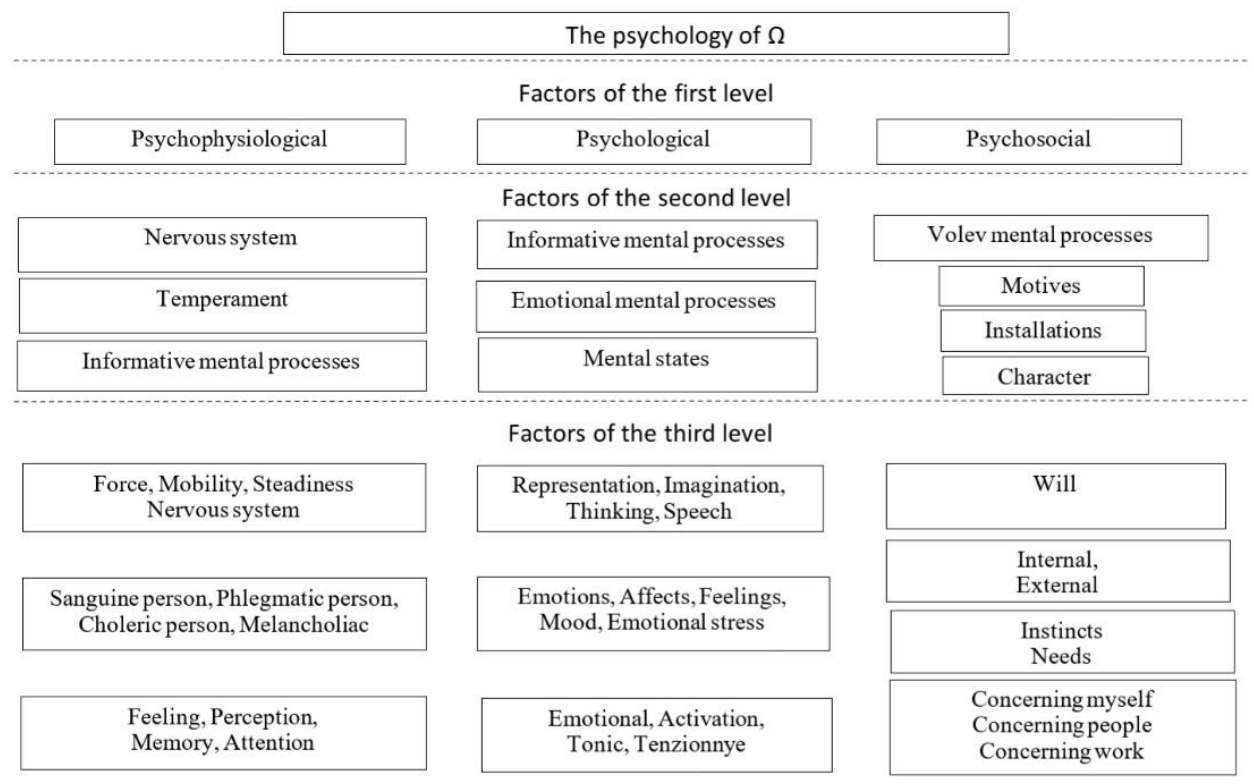

Factors $\Omega$ model. Factors of the first level reflect the main levels of $\Omega$. Factors of the second level open factors of the first level. Factors of the third level open factors of the second level.

Fig. 4. The developed factorial model of psychology of $\Omega$.

The given planes of studying levels $\Omega$ the person are connected among themselves by feedback. It is impossible to investigate, for example, psychophysiological $\Omega$ the person in a separation from psychological $\Omega$ the person or psychosocial $\Omega$ the person. At the same time each level has the markers on which the psychologist can estimate $\Omega$ at any given level to the physiopsychosocial system of the person. Psychophysiological level is the nervous system in determining the individual's mental activity. Psychological level is emotions that form the mental state of the individual. Psychosocial level is volitional manifestation of the orientation of the labor subject. Depending on the studied level $\Omega$ the person, also that party of the person is concretized that it is subject to study. Therefore, $\Omega$ the person are $\Omega$ the individual, the personality, the subject of work. If it is studied $\Omega$ the person at the psychophysiological level, then it is first of all about the individual. If it is studied $\Omega$ the person at the psychological level, then it is first of all about the personality. If it is studied $\Omega$ the person at the psychosocial level, then it is first of all about the subject of work. Stated important to understand to the psychologist and the scientist at assessment $\Omega$ the person. Existence of the uniform and conventional paradigm of a research $\Omega$ the person will promote: to right statement of hypotheses on study $\Omega$ the person; to selection of the most informative techniques of a research, analysis, diagnostics, development and correction $\Omega$ person; to the developed empirical data.

We presented a research algorithm matrix on the second stage $\Omega$ the person (table 1). The matrix specifies that factors of psychophysiological, psychological and psychosocial levels correspond psychophysiological $\Omega$, psychological $\Omega$ and psychosocial $\Omega$. We allocate in a matrix (table 1) the main and minor markers depending on a segment of a research (formula 1):

$$
\left|\begin{array}{lll}
1-1 & 2-1 & 3-1 \\
1-2 & 2-2 & 3-2 \\
1-3 & 2-3 & 3-3
\end{array}\right|
$$

In a formula the main markers are highlighted with 1 gray color. 
Each marker of a segment of a matrix (1-1, 1-2, 1-3; 2-1, 2-2, 2-3; 3-1, 3-2, 3-3) has to be defined by the corresponding methods of the analysis and diagnostics and also methods of development and correction, answering two blocks of questions (table 3). The first block of questions: "What is analyzed and diagnosed? How it is analyzed and diagnosed?". The second block of questions: "What develops and adjusted? How does it develop and adjusted?". That is, it is possible to write down formula 1 in the form of the following matrix:

$$
\left|\begin{array}{lll}
\Omega \varphi=f(\varphi) & \Omega \psi=f(\varphi) & \Omega s=f(s) \\
\Omega \varphi=f(\psi) & \Omega \psi=f(\psi) & \Omega s=f(s) \\
\Omega \varphi=f(s) & \Omega \psi=f(s) & \Omega s=f(s)
\end{array}\right|
$$

Where,

$f$ - dependence of one set $(\Omega \varphi, \Omega \psi$, and $\Omega$ s) from another ( $\varphi, \psi$, and s);

$\Omega \varphi-$ a dependent variable (a dependent variable from at the psychophysiological level $(\varphi))$;

$\Omega \psi-$ a dependent variable (a dependent variable from at the psychological level $(\psi)$ );

$\Omega s-$ a dependent variable (a dependent variable from at the psychosocial level (s));

$(\varphi)-$ a function argument (the independent variable consisting of a set (n) of psychophysiological markers (m));

$(\psi)$ - a function argument (the independent variable consisting of a set (n) of psychological markers (m));

(s) - a function argument (the independent variable consisting of a set (n) of psychosocial markers (m)).

It is possible to write down a formula (2) as follows:

$$
\Omega \varphi, \Omega \psi, \Omega s=\sum_{n}^{m} f(\varphi), f(\psi), f(s)
$$

Where,

$\mathrm{n}$ - quantity of markers $(\varphi, \psi$, and $\mathrm{s})$;

$\mathrm{m}-$ the numerical size of any given marker $(\varphi, \psi$, and $s)$ determined by any given method of the analysis and diagnostics.

Table 1, 2 and formulas 1-3 point that there have to be conventional methods of the analysis and diagnostics $\Omega$ the person, the having numerical values. Then these methods will be objective at a research $\Omega$ the person. Methods not having numerical values, it is necessary to carry to subjective methods. These methods have minor character for a research and are only addition at a research $\Omega$ the person. Stated brings to a thought that it is necessary to understand what place the existing methods of the analysis, diagnostics, development, and adjustment $\Omega$ take the person in the matrix offered by us. Then it will be clear what segments of a matrix have no given methods of the analysis, diagnostics, development, and adjustment $\Omega$ the person. The matrix allows to structure the accumulated experience of psychology on study $\Omega$ the person. However, it is a subject of separate article.

\section{Conclusions}

At all times the central link are: 1) surrounding reality (space and time); 2) the society from intelligence of each person. In the turbulent changing world the psychology of the $21 \mathrm{st}$ century is the "Psychology $\Omega$ " accumulating theories of many directions of this science. "Psychology $\Omega$ " - "here and now". In modern society of people becomes a link of the digital world. Improving the digital world, it changes surrounding reality, doing it highly technological. The high technological effectiveness digitizes intelligence of each person. "Cloth" of society digitalization, changing psychology of self-identification of the person. The individual, the personality and the subject of work digitalization. All physiopsychosocial 
system of the person digitalization. And it is necessary to understand ability of the person to maintaining health as $\Omega$ at the psychophysiological, psychological and psychosocial levels of activity under the influence of destroyers.

In the conclusion we will note that it will be interesting to author of article to receive from researchers who are engaged in studying a phenomenon $\Omega$ the person, feedback not only on the offered matrix, but also other published ideas of the author. Remarks and offers will be considered in development of a uniform paradigm of studying a phenomenon $\Omega$ the person and included in the subsequent articles on this subject.

\section{References}

1. L. Wu, Y. Tan, Y. Liu, Factor structure and psychometric evaluation of the ConnorDavidson resilience scale in a new employee population of China, BMC Psychiatry 17, 49 (2017) DOI 10.1186/s12888-017-1219-0

2. V.V. Kazankov, Bulletin of the Leningrad State University. A.S. Pushkin, 65-76 (2010) doi.org/10.24412/Ff8E8mTGxIU

3. E. Barasa, R. Mbau, L. Gilson, What is resilience and how can it be nurtured? A systematic review of empirical literature on organizational resilience, Int J Health Policy Manag. 7(6), 491-503 (2018) doi:10.15171/ijhpm.2018.06

4. V. Kazankov, The psychology of ustoychivost': a conceptual model of human ustoychivost', E3S Web of Conferences 210, 20020 (2020)

5. V. Kazankov, V. Gubin, Psychology of ustoychivost': numerical scale for assessing human's ustoychivost' according to the golden ratio rule, E3S Web of Conferences 210 , 20018 (2020)

6. A. Chmitorz, M. Wenzel, R.D. Stieglitz, A. Kunzler, C. Bagusat, I. Helmreich, et al., Population-based validation of a German version of the Brief Resilience Scale. PLoS ONE 13(2), e0192761 (2018) https://doi.org/10.1371/journal. pone.0192761

7. J. Scali J, Gandubert C, Ritchie K, Soulier M, Ancelin M-L, et al., Measuring Resilience in Adult Women Using the 10-Items Connor-Davidson Resilience Scale (CD-RISC). Role of Trauma Exposure and Anxiety Disorders, PLoS ONE 7(6), e39879 (2012) doi:10.1371/journal.pone.0039879

8. M.A. Harris, C.E. Brett, Personality Stability From Age 14 to Age 77 Years, Psychology and Aging 31, 8, 862-874 (2016) http://dx.doi.org/10.1037/pag0000133.supp

9. S. Yasien, J.A. Nasir, T. Shaheen, Relationship between psychological distress and resilience in rescue workers, Saudi. Med. J. 37(7), 778-782 (2016) doi: 10.15537/smj.2016.7.15004

10. L. Campbell-Sills, M.B. Stein, J. Trauma, Stress 20(6), 1019-1028 (2007) doi.org/10.1002/jts.20271

11. Y. Xie, L. Peng, X. Zuo, M. Li, The Psychometric Evaluation of the Connor-Davidson Resilience Scale Using a Chinese Military Sample, PLoS ONE 11(2), e0148843 (2016) doi:10.1371/journal. pone.0148843

12. G.A. Bonnano, A.D. Mancini, Pediatrics 121, 369-375 (2008) doi: 10.1542/peds.20071648

13. M. Pęciłł, The concept of resilience in OSH management: a review of approaches, International Journal of Occupational Safety and Ergonomics 22:2, 291-300 (2016) DOI: $10.1080 / 10803548.2015 .1126142$ 
14. S. Bruce, D.G. Jason, C. Nasca, Recognizing resilience: Learning from the effects of stress on the brain, Neurobiology of Stress 1 (1), 1-11 (2015) http://dx.doi.org/10.1016/j.ynstr.2014.09.001 2352-2895

15. G.A. Bonanno, E.D. Diminich, Annual Research Review: Positive adjustment to adversity - Trajectories of minimal-impact resilience and emergent resilience, J. Child. Psychol. Psychiatry 54(4), 378-401 (2013) doi:10.1111/jcpp.12021

16. M. Scheffera, J.E. Bolhuisb, D. Borsboom, T.G. Buchman, Quantifying resilience of humans and other animals, Perspective 115, 47, 11883-11890 (2018) www.pnas.org/cgi/doi/10.1073/pnas.1810630115

17. A.Sisto, F.Vicinanza, L.L. Campanozzi, G. Ricci, D. Tartaglini, V. Tambone, Towards a Transversal Definition of Psychological Resilience: A Literature Review, Medicina 55, 745 (2019) doi:10.3390/medicina55110745

18. D. Jackson, A. Firtko, M. Edenborough, Personal resilience as a strategy for surviving and thriving in the face of workplace adversity: a literature review, Journal of Advanced Nursing 60(1), 1-9 (2007) doi: 10.1111/j.1365-2648.2007.04412.x

19. S.M. Southwick, G.A. Bonanno, A.S. Masten, C. Panter-Brick, R. Yehuda, Resilience definitions, theory, and challenges: interdisciplinary perspectives, European Journal of Psychotraumatology 5, 25338 (2014) http://dx.doi.org/10.3402/ejpt.v5.25338

20. D. Fletcher, M. Sarkar, Psychological resilience: A review and critique of definitions, concepts, and theory, Eur. Psych. 18(1), 12-23 (2013) doi: 10.1027/1016-9040/a000124

21. S. Meggen Tucker, Development Of The Family Resilience Assessment Scale To Identify Family Resilience Constructs. A Dissertation (University Of Florida, 2005) https://ufdc.ufl.edu/UFE0012882/00001 